Original Article

\title{
EFFECT OF DIFFERENT FORMULATION VARIABLES ON RELEASE CHARACTERISTICS OF GASTRO-FLOATING MICROSPHERES OF ETHYL CELLULOSE/CARBOPOL 934P ENCAPSULATING SORAFENIB
}

\author{
MAHMOUD M. AHMED* \\ *Department of Pharmaceutics and Clinical Pharmacy, Faculty of Pharmacy, Sohag University, Sohag, Egypt \\ Email: mahmoudalmenshawy@pharm.sohag.edu.eg
}

Received: 24 May 2019, Revised and Accepted: 13 Sep 2019

ABSTRACT

Objective: The aim of this study is to prepare floating hollow microspheres encapsulating Sorafenib (SFN) to enhance its oral bioavailability.

Methods: Gastro-floating hollow adhesive microspheres containing SFN were produced by using an emulsion solvent evaporation technique with ether and ethanol as solvents. Ethyl cellulose and carbopol 934P were used as the encapsulating carriers. The effects of formulation parameters like, solvent volume ratio, and drug to polymer ratio (D: P ratio), encapsulation efficiency percentage EE\%, floating percentage, and release of SFN after $12 \mathrm{~h}\left(\operatorname{Rel}_{12}\right)$ were investigated and analyzed using a $\left(3^{2}\right)$ full factorial design.

Results: The floating percentage of the microspheres was found to be $76.5 \%$. The in vitro drug release from these hollow microspheres followed the Higuchi model equation. The in vivo results showed that approximately 1.96 -fold improvement in the relative bioavailability of the microspheres compared with that of the commercial tablet.

Conclusion: The results demonstrate that the hollow microspheres with good gastro-floating ability are a promising delivery system to enhance SFN bioavailability.

Keywords: Sorafenib, Gastro-floating, Microspheres, Ethyl cellulose, Carbopol 934P, Factorial design

(C) 2019 The Authors. Published by Innovare Academic Sciences Pvt Ltd. This is an open access article under the CC BY license (http://creativecommons.org/licenses/by/4.0/) DOI: http://dx.doi.org/10.22159/ijpps.2019v11i10.34290

\section{INTRODUCTION}

Sorafenib (SFN) is an endorsed drug to treat hepatocellular carcinoma (HCC) [1]. SFN is a multi-kinase inhibitor that prolongs overall survival and postpones the opportunity to progression in patients with advanced HCC who are not candidates for remedial treatment [2]. SFN is a weakly basic drug with a higher absorption rate under acidic conditions in the stomach than in the intestine [3] Floating drug delivery systems are a dosage formulation that floats on the gastric juice and persistently releases the drugs [4]. The floating systems show a bulk density of less than gastric fluids and remain buoyant in the stomach for a longer period of time without affecting the gastric emptying rate [5]. The drug is released slowly when the system floats in the gastric fluid at the desired rate [6]. This results in increased gastric retention time and better control of fluctuations in the plasma drug concentration [7]. A floating drug delivery system could be suitable for SFN with a definite absorption zone in the stomach [7].

Orally administrated SFN exhibited large individual differences in bioavailability because of the variable gastrointestinal transit time of a single tablet [8]. On the contrary, a multiple-unit floating drug delivery system could reduce inter-and intra-subject variability in drug absorption and dose dumping $[9,10]$. There is no report on SFN containing hollow microspheres.

Hollow microspheres are multi-unit floating formulations that release the drug more uniformly when passing through the gastrointestinal tract [11]. The more uniform the distribution of these multi-unit microspheres in the gastrointestinal tract, the more reproducible the drug absorption and the less local irritation caused $[12,13]$.

Herein, as illustrated in Scheme 1, we provide a protocol to prepare gastro-floating hollow adhesive microspheres of EC/Carbopol 934P encapsulating SFN in order to achieve a sustained release of drug in the stomach. Ethyl cellulose (EC) was used as the polymer because of its water insolubility, which will help in sustaining the drug release for a longer time [14]. Carbopol 934P is an anionic polymer with mucoadhesive properties [15].

The objective of this study was to develop floating gastro-retentive hollow adhesive microspheres to increase their residence time in the stomach, which may result in an enhanced bioavailability.

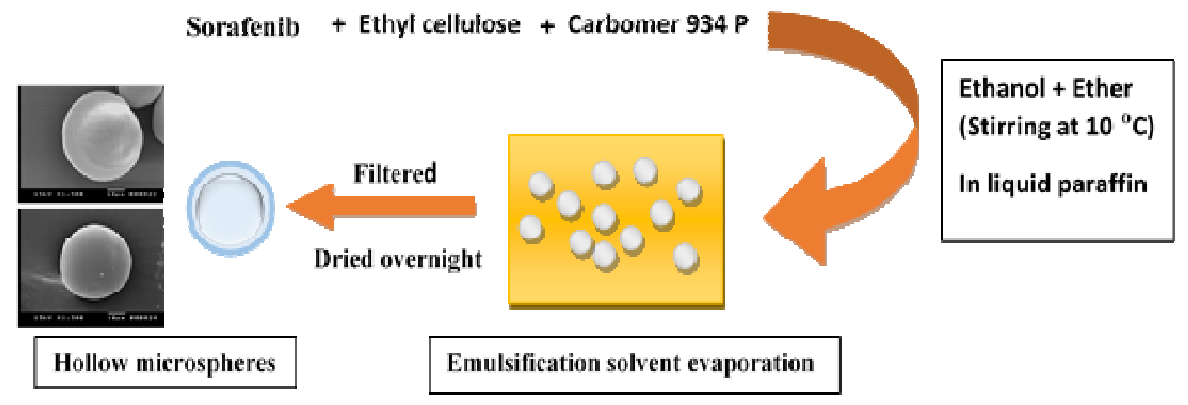

Scheme 1: Illustration of the preparation process of the gastro-floating hollow adhesive microspheres of EC/Carbopol 934P encapsulating SFN 


\section{MATERIALS AND METHODS}

\section{Chemicals and reagents}

SFN and EC (Sigma Chem. Co., St. Louis. USA); Carbopol 934P (United States Lubrizol); Span 80, and cyclohexane Sigma Chem. Co., Stoneham (Germany); Liquid paraffin, and magnesium stearate (ElGomhoria Chem. Co., Ltd). Anhydrous ethanol, anhydrous diethyl ether, hydrochloric acid, N-hexane, ammonium acetate, acetonitrile and acetone, El-Nasr Pharm. Chem. Co., Ltd).

\section{Design of the experiment}

In the pre-optimization studies, the optimal concentrations of Span 80 and magnesium stearate were investigated based on the results got from drug loading encapsulation efficiency and appearance. A two-factors, three-levels full factorial design (FFD) was employed to optimize the composition of the gastro-floating microspheres [16, 17]. The experiments were performed in triplicate. The $D$ : $P$ ratio $(A)$, and ether to ethanol volume ratio $(B)$ were independent variables at three levels. The percentage drug entrapment efficiency, percentage drug floating and percentage release after $12 \mathrm{~h}$ were selected as the dependent variables. Table 1 shows the full factorial design. The significance levels of different influencing factors were tested by range comprehensive analysis.

\section{Preparation of microspheres}

Emulsion solvent evaporation technique was used to prepare the floating hollow adhesive microspheres containing SFN [18]. Briefly, polymer blends of EC and carbopol 934P were dissolved in a mixture of ethanol and diethyl ether. The required amount of SFN was dispersed into the solution with stirring at $10^{\circ} \mathrm{C}$. The polymer and drug solution was added slowly to liquid paraffin containing Span 80 and magnesium stearate (soothing agent) with stirring at $400 \mathrm{rpm}$ for $30 \mathrm{~min}$ at $10^{\circ} \mathrm{C}$ until a stable emulsion was formed. The resulted emulsion was continuously stirred at $30^{\circ} \mathrm{C}$ for $45 \mathrm{~min}$. During this period, the volatile solvent evaporated and microspheres were obtained. The microspheres were filtered and washed with n-hexane and kept overnight at $30^{\circ} \mathrm{C}$. The dried microspheres were stored in desiccators at room temperature until use.

Table 1: $\left(3^{2}\right)$ Full Factorial design of different formulae of SFN microspheres

\begin{tabular}{lll}
\hline Formula No. & Drug: polymer ratio (A) & Ether: ethanol (B) (v/v) \\
\hline F1 & $0.15: 1(-1)$ & $7.5: 2.5(-1)$ \\
F2 & $0.20: 1(0)$ & $7.5: 2.5(-1)$ \\
F3 & $0.25: 1(1)$ & $7.5: 2.5(-1)$ \\
F4 & $0.15: 1(-1)$ & $8: 2(0)$ \\
F5 & $0.20: 1(0)$ & $8: 2(0)$ \\
F6 & $0.25: 1(1)$ & $8: 2(0)$ \\
F7 & $0.15: 1(-1)$ & $8.5: 1.5(1)$ \\
F8 & $0.20: 1(0)$ & $8.5: 1.5(1)$ \\
F9 & $0.25: 1(1)$ & $8.5: 1.5(1)$ \\
\hline
\end{tabular}

Independent variables Level

\begin{tabular}{|c|c|c|c|}
\hline Ether: Ethanol (v/v) & $+1=8.5: 1.5$ & $0=8: 2$ & $-1=7.5: 2.5$ \\
\hline Drug-polymer ratio & $+1=0.25: 1$ & $0=0.20: 1$ & $-1=0.15: 1$ \\
\hline
\end{tabular}

\section{Particle size and shape}

The size distribution of the microspheres was determined using an optical microscope (Leica Microsystems, Heerbrugg, Switzerland). Microsphere morphology and shape was described in terms of aspect ratio (AR) and circularity (C). The mean size distribution was calculated by measuring $200-300$ particles.

Microsphere morphological examination was also performed using scanning electron microscopy (SEM, Jeol, JSM-5200, Tokyo, Japan) at $15 \mathrm{keV}$. Samples of dried floating hollow microspheres were mounted onto stubs and sputter-coated with gold in a vacuum evaporator.

\section{Determination of encapsulation efficiency and drug loading}

The encapsulation efficiency percentage (EE \%) was calculated according to the following equation:

\section{$\mathrm{EE} \%=\mathrm{W}_{1} / \mathrm{W}_{2} \approx 100$}

Where $W_{1}$ is the total amount of drug in the microsphere and $W_{2}$ is the total quantity of the drug added initially. The drug loading (DL) of the hollow microspheres was calculated as follows [19]:

DL $(\%)=$ (mass of SFN in microspheres/mass of micnopheres) $\times 100$

The SFN-loaded hollow adhesive microspheres $(10 \mathrm{mg})$ were ground

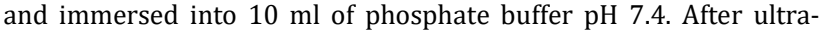
sonication, the concentration of SFN was determined using a UVvisible spectrophotometer (Shimadzu UV-1700 series) at $265 \mathrm{~nm}$.

\section{In vitro floating ability}

The floating behavior of the SFN microspheres was studied according to the method described in a previous report [11]. Briefly, 100 individual microspheres were added to $900 \mathrm{ml}$ of enzyme-free simulated gastric fluid $(\mathrm{HCl} / \mathrm{NaCl}$ solution containing the surfactant
Tween-80 at a concentration of $0.02 \%$; $\mathrm{pH} 1.2$ ) or enzyme-free simulated intestinal fluid of $\mathrm{pH} 7.4 \quad\left(\mathrm{KH}_{2} \mathrm{PO}_{4} / \mathrm{NaOH}\right.$ solution containing $0.02 \%$ Tween-80) at $37 \mathrm{~T} 0.5{ }^{\circ} \mathrm{C}$. The dispersing medium was agitated at $100 \mathrm{rpm}$ with a standard paddle. The floating ability was evaluated based on the number of microspheres that remained buoyant in the medium.

\section{In vitro drug release studies}

Dissolution testing of the prepared microspheres equivalent to 50 $\mathrm{mg}$ of SFN was performed with the rotating basket apparatus according to USP XXIV apparatus 2 [19].

First, $900 \mathrm{ml}$ of $0.1 \mathrm{~N} \mathrm{HCl}$, was used as the release medium for $12 \mathrm{~h}$. An amount of floating hollow microspheres equivalent to $50 \mathrm{mg}$ of SFN was placed in a muslin cloth having a smaller mesh size than the microspheres. The mesh was tied with a nylon thread to avoid the escape of any microspheres, and a glass bead was placed in the mesh to induce sinking of the microspheres in the dissolution medium. Filtered samples, $3 \mathrm{ml}$ each, were removed at $1,2,4,6,8,10$, and 12 $\mathrm{h}$. The samples were diluted appropriately with the release medium, and absorbance was measured at $265 \mathrm{~nm}$. For SFN using a UV spectrophotometer (Shimadzu UV-1700 series). The withdrawn samples were replaced with equal volumes of the release medium kept at $37^{\circ} \mathrm{C}$. All experiments were conducted in triplicate [20]. The data acquired from the release studies were analyzed kinetically using various mathematical models including zero-order, first-order, and Higuchi models $[21,22]$.

\section{Pharmacokinetic studies}

Male healthy rats weighing $280 \pm 20$ g were selected randomly and divided equally into two groups $(n=6)$. All animal procedures were performed after approval by the Institutional Animal Care and Use Committee of Faculty of Pharmacy, Minia University, Minia, Egypt. 
Rats were fasted for $24 \mathrm{~h}$ prior to drug administration and water was freely available. One group was given gastric lavage with ordinary tablets (tablets were ground into a fine powder, $0.5 \% \mathrm{CMC}$ $\mathrm{Na}$ solution was suspended), and the other group was given the selfmade microsphere suspension (0.5\% CMC-Na solution suspension) with the dose equivalent to $10 \mathrm{mg} \mathrm{kg}^{-1} \mathrm{SFN}$. Blood samples $(0.5 \mathrm{ml})$ were collected by retro-orbital puncture at $0.25,0.5,1,1.5,2,3,4,6$, 8,12 and $24 \mathrm{~h}$ after administration. Then, plasma was obtained from the blood samples by centrifugation at $4000 \mathrm{rpm}$ for $10 \mathrm{~min}$. The concentration of SFN in rat plasma was determined by HPLC on C18 column using a mobile phase of acetonitrile and $20 \mathrm{mmol} / \mathrm{l}$ ammonium acetate in a proportion 53:47 (v/v) pumped at a constant flow rate of $1.2 \mathrm{ml} / \mathrm{min}$. Quantification was performed at $265 \mathrm{~nm}[22]$.

\section{RESULTS AND DISCUSSION}

\section{Preparation of floating hollow adhesive microspheres}

The emulsion solvent diffusion evaporation method was employed to develop SFN containing hollow microspheres as a floating drug delivery system. Liquid paraffin was used as the dispersion medium, and a mixture of ether and ethanol was used as the internal phase [23]. The ether could quickly diffuse into the liquid paraffin, resulting in a polymer instantly solidifying into a thin film. The microspheres exhibited better morphology when the ratio of inner and outer phases was 1: 10 . When the internal phase ratio was increased, the microspheres became more cohesive. EC was used as the carrier polymer to sustain the drug release for a longer time with film-forming ability and stability in the stomach. Carbopol 934P is an anionic polymer with adhesive properties [24].

Microspheres appearance, drug loading amount and encapsulation efficiency of SFN are affected by Span 80 concentration, which acted as an emulsifying agent. Drug loading amount was elevated with increasing content of Span 80 up to 1.5\%. However, once the concentration exceeded $1.5 \%$, the appearance of the microspheres was irregular and slightly conglutinated.

Magnesium stearate acted as a droplet stabilizer to prevent droplet coalescence during emulsification and solvent evaporation, and its concentration in liquid paraffin was varied to explore its effects on the appearance, drug loading amount and encapsulation efficiency of the microspheres [18]. The microsphere appearance was spherical without conglutination when the magnesium stearate concentration was adjusted to $0.02 \%$.

\section{Characterization of the microspheres}

The particle size distribution of the microspheres is shown in fig. 1 and the mean diameter was around $362 \mathrm{um}$. The morphology of the surface and was confirmed by SEM. The SEM photographs in fig. 2A and $B$ revealed that the microsphere was spherical with a smooth intact surface with no holes and possessed a hollow core with buoyancy ability.

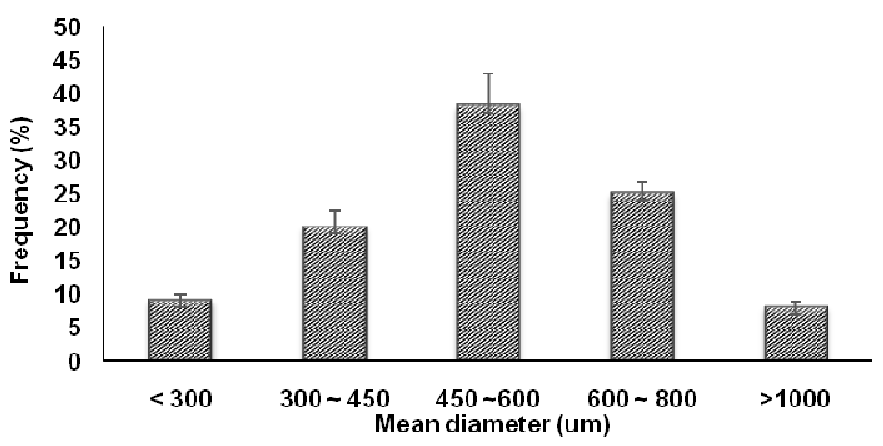

Fig. 1: The size distribution of the gastro-floating hollow adhesive microspheres (mean $\pm S D, n=5$ )
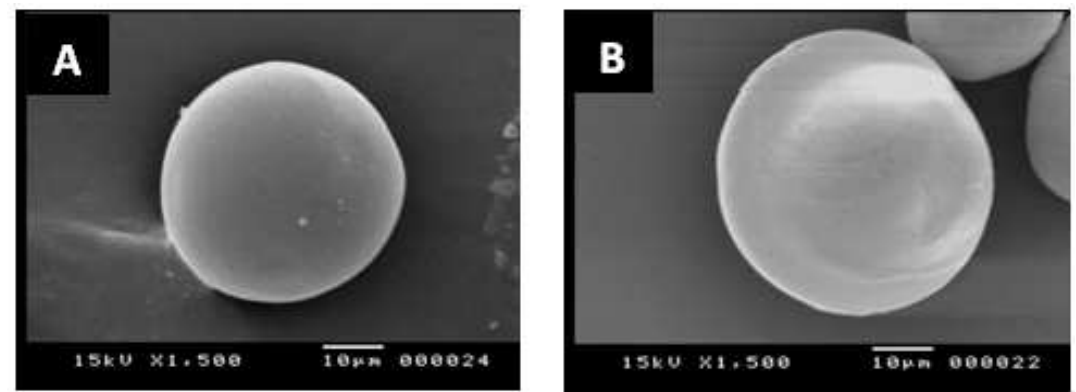

Fig. 2: Scanning electron microphotographs of a floating hollow adhesive microsphere

\section{The results of the optimization}

Table 2 shows the range analysis results of the effects of different factors. For the $\left(3^{2}\right)$ factorial design, nine experimental trial formulations were proposed. Range analysis was used to clarify the effects of different factors on encapsulation effciency, floating effciency and SFN release after $12 \mathrm{~h}$. The range value $(R)$ for each factor was the difference between the maximal and minimal values of three levels. A higher $R$-value of a factor represents its greater effect on the encapsulation efficiency, floating efficiency and SFN release, and vice versa. Thus, the factors eliciting the above values in order were $B$ (the ether/ethanol volume ratio), $B$ (the drug to polymer ratio). According to the $K$ values of the two factors, the optimum condition was $B_{0} A_{1}$, corresponding to 0.20: 1 ether/ethanol volume ratio, and 8.5: $1.5 \mathrm{D}$ : $\mathrm{P}$ ratio. Three batches of microspheres were prepared based on the optimized formulation, and their physicochemical characteristics were studied in vitro. The optimized microspheres containing SFN exhibited an entrapment efficiency of $82 \%$, floating percentage of $78 \%$ and release after $12 \mathrm{~h} 92 \%$.

\section{Encapsulation Efficiency}

The effect of changing the drug to polymer ratio on $\mathrm{EE} \%$ was investigated, at each D: P ratio, using the ANOVA test. The EE\% ranged from $67.7 \pm 3.8$ to $95.6 \pm 5.36$. The output shows the results of fitting a multiple linear regression model to describe the relationship between $\mathrm{D}$ : $\mathrm{P}$ ratio and $\mathrm{EE} \%$. The equation of the fitted model is

$$
Y_{\sharp}=0.461394-0.00564972 A \ldots \ldots \text {.... } 1
$$


Since the P-value in the ANOVA table is less than 0.05 , there is a statistically significant relationship between the variables at the $95 \%$ or higher confidence level. The output shows the results of fitting a multiple linear regression model to describe the relationship between the ether: ethanol ratio and drug EE\%. The equation of the fitted model is

$$
Y_{1}=9.91996-0.121469 \mathrm{~B}
$$

There is a statistically significant relationship between the variables at the $99 \%$ confidence level $\left({ }^{* * *} \mathrm{P}>0.01\right)$.

The 3-D plot (fig. 3) showed that. The improvement in EE\% with increased ether: ethanol ratio was due to the fact that more amount of the drug get dissolved and incorporated in the polymer matrix as ether volume increased. EE\% decreased from $83.2 \pm 4.10$ to $67.7 \pm 3.80$ and from $95.6 \pm 5.36$ to $79.6 \pm 4.98$ at lower and higher levels of D: P ratio with constant ether: ethanol ratio. These results are because of decreased polymers concentration that allows less amount of SFN to be microencapsulated within the polymer matrix.

Table 2: Factor combinations and response parameters of SFN microspheres prepared as $3^{2}$ factorial design

\begin{tabular}{|c|c|c|c|c|c|}
\hline \multirow{2}{*}{ Formulation no. } & \multicolumn{2}{|l|}{ Factors } & \multirow{2}{*}{$\mathrm{EE} \%(\% \mathrm{w} / \mathrm{w})^{a}$} & \multirow{2}{*}{ Floating percentage $(\%)^{a}$} & \multirow[t]{2}{*}{$\operatorname{Rel}_{12}{ }^{\mathrm{a}}$} \\
\hline & A & B & & & \\
\hline F-1 & $0.15: 1(-1)$ & $7.5: 2.5(-1)$ & $83.2 \pm 4.10$ & $68.43 \pm 1.21$ & $57.15 \pm 2.76$ \\
\hline F-2 & $0.15: 1(-1)$ & $8.0: 2.0(0)$ & $89.3 \pm 4.24$ & $93.07 \pm 1.04$ & $65.06 \pm 2.65$ \\
\hline F-3 & $0.15: 1(-1)$ & 8.5: $1.5(1)$ & $95.6 \pm 5.36$ & $95.23 \pm 1.32$ & $76.03 \pm 2.63$ \\
\hline F-4 & $0.20: 1(0)$ & $7.5: 2.5(-1)$ & $73.7 \pm 6.03$ & $62.32 \pm 1.62$ & $61.31 \pm 2.89$ \\
\hline F-5 & $0.20: 1(0)$ & $8.0: 2.0(0)$ & $80.5 \pm 4.59$ & $70.23 \pm 1.65$ & $79.98 \pm 3.01$ \\
\hline F-6 & $0.20: 1(0)$ & 8.5: $1.5(1)$ & $82.1 \pm 3.76$ & $80.09 \pm 1.85$ & $88.27 \pm 3.67$ \\
\hline F-7 & $0.25: 1$ (1) & $7.5: 2.5(-1)$ & $67.7 \pm 3.80$ & $65.31 \pm 1.33$ & $79.27 \pm 2.46$ \\
\hline F-8 & $0.25: 1$ (1) & $8.0: 2.0(0)$ & $72.5 \pm 3.22$ & $75.25 \pm 1.08$ & $87.41 \pm 1.87$ \\
\hline F-9 & $0.25: 1(1)$ & 8.5: $1.5(1)$ & $79.6 \pm 4.98$ & $81.21 \pm 1.55$ & $94.89 \pm 2.01$ \\
\hline
\end{tabular}

mean $\pm S D, n=5$, the parentheses in the data represent the decoded factor levels. A represents D: P ratio; B represents the ether: ethanol ratio. EE $\%=$

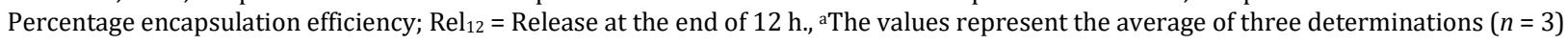

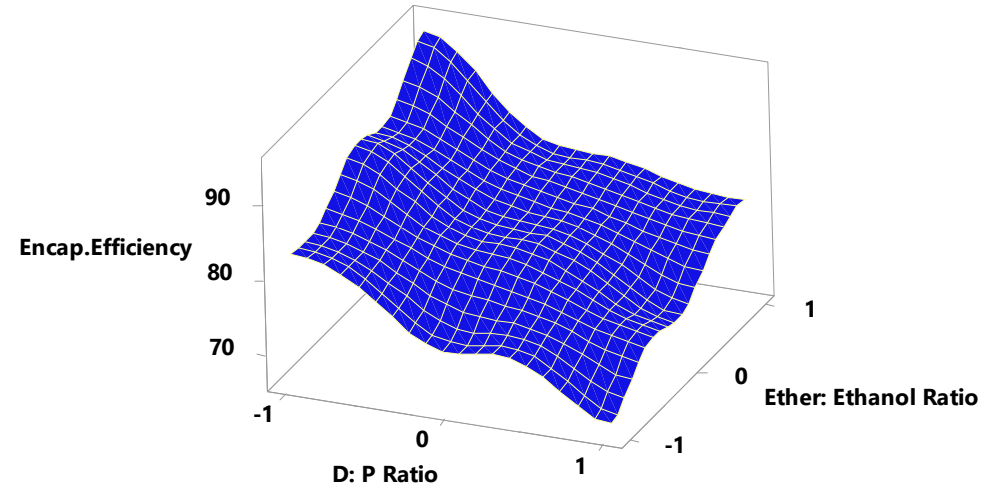

Fig. 3: Three-dimensional plot for the effect of D: $P$ ratio $(A)$ and Ether: Ethanol ratio $(B)$ on EE \%

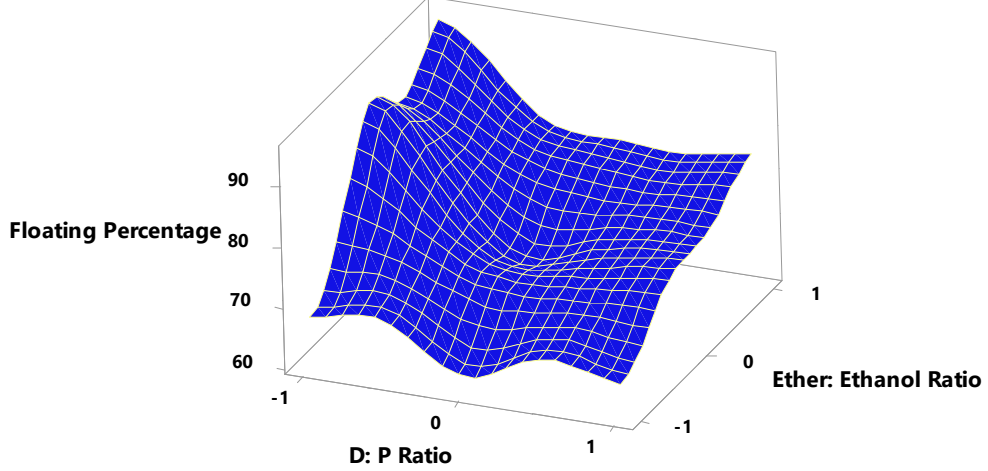

Fig. 4: Three-dimensional plot for the effect of D: P ratio $(A)$ and ether: ethanol ratio $(B)$ on floating \%

\section{In vitro floating study}

The floating test was used to investigate the floating ability of the hollow gastro-floating microspheres. The in vitro floating efficiency investigation showed that over $76.5 \%$ of the SFN hollow microspheres remained floating in the simulated gastric fluid for 12 h. This might contribute to the sustained release of SFN encapsulated in the microspheres.

The 3-D plot (fig. 4) showed that the improvement in floating percentage with increased ether: ethanol ratio may be for fast evaporation of ether content as its ratio increased. EE\% decreased at 
lower and higher levels of D: P ratio with constant ether: ethanol ratio. These results are because of decreased polymers content and consequently decreased microspheres density that allows buoyancy of the hollow microspheres for a long period of time.

\section{In vitro release study}

The best formulae for the in vitro release after whole dissolution period (12 h) were observed to be F9, F6, F8, F5, F7, F3, F2, F4, and F1. The equation of the fitted model which study the effect of D: P Ratio $(A)$ and ether: ethanol ratio $(B)$ on drug release after $12 \mathrm{~h}$ is (Release $12 \mathrm{~h}=27.899-3.5 \mathrm{~A}+429250$ ), Since the $\mathrm{P}$-value in the ANOVA table is less than $0.01\left({ }^{* *} \mathrm{P}>0.01\right)$, there is a statistically significant relationship between the variables at the $99 \%$ confidence level. The D: P ratios as well as ether: ethanol ratio were found to have a positive influence on the drug release. The response surface plot (fig. 5) illustrate that the percentage drug release at the end of $12 \mathrm{~h}$ decreased from $57.15 \pm 2.76 \pm 1.54 \%$ to $79.27 \pm 2.46 \pm 1.23$ and from $76.03 \pm 2.63$ to $94.89 \pm 2.01 \pm 1.42 \%$ at low and high levels of D: P ratio, respectively as the polymer content decreased. This can be due to increased diffusion of the drug from polymeric matrices, which left behind fewer drug crystals on the surface with the decrease in the polymer content.

The levels of ether: ethanol ratio were found to have a positive influence on the drug release after $12 \mathrm{~h}$. It was evident from the 3-D plots that the percentage drug release increased from $57.15 \pm 2.76$ to $76.03 \pm 2.63$ and from $79.27 \pm 2.46$ to $94.89 \pm 2.01$ at low and high ether: ethanol ratio respectively, fig. 5 . This increase in drug release was due to the increase in ether content, which upon evaporation increased the permeability of the polymer matrix.

The release data of SFN from floating microspheres prepared with different process variables were analyzed according to zero and first-order kinetics as well as, Higushi diffusion-controlled mechanism table 3 . The release order of the drug was determined. It was found that the drug was released from the microspheres according to Higushi diffusion pattern, at different drugs to polymer ratios. The release medium dissolves the drug after penetrating the microcapsule wall by allowing the dissolved drug to diffuse out due to concentration gradient established between the interior of the microspheres and the release medium.

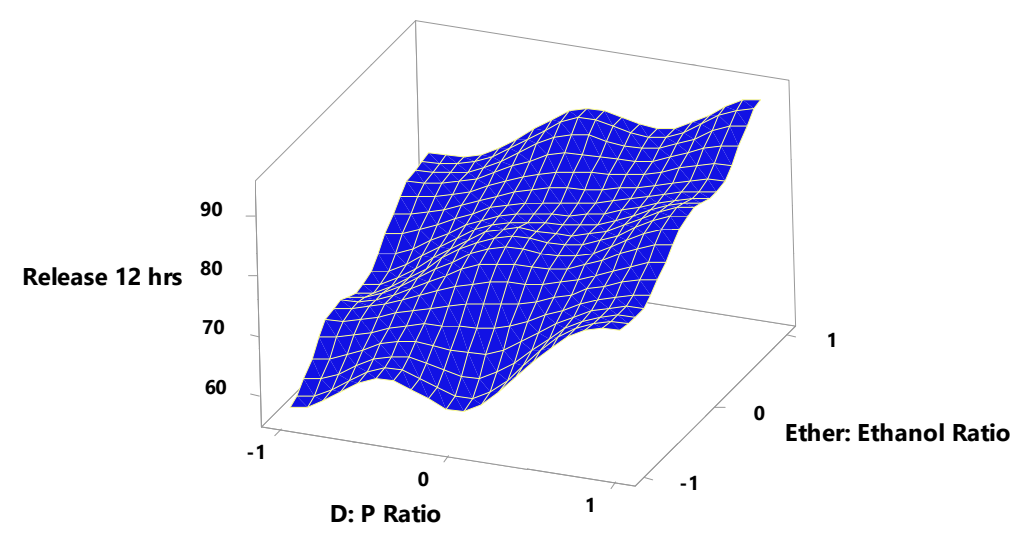

Fig. 5: Three-dimensional plot for the effect of D: P ratio $(A)$ and Ether: Ethanol ratio $(B)$ on release $12 \mathrm{~h} \%$

Table 3: Analysis of the release data for SFN microspheres

\begin{tabular}{|c|c|c|c|c|c|c|c|c|c|c|}
\hline \multirow{3}{*}{$\begin{array}{l}\text { Formula no. } \\
\text { Zero-order }\end{array}$} & & F1 & F2 & F3 & F4 & F5 & F6 & F7 & F8 & F9 \\
\hline & $\mathrm{K}_{\mathrm{z}}$ & 8.148 & 10.50 & 7.108 & 8.837 & 8.781 & 9.482 & 6.44 & 5.215 & 9.323 \\
\hline & $\mathrm{R}_{\mathrm{z}}$ & 0.924 & 0.990 & 0.967 & 0.976 & 0.971 & 0.985 & 0.960 & 0.976 & 0.976 \\
\hline \multirow[t]{2}{*}{ First-order } & $K_{f}$ & 0.139 & 0.291 & 0.127 & 0.171 & 0.167 & 0.217 & 0.104 & 0.074 & 0.203 \\
\hline & $\mathrm{R}_{\mathrm{f}}$ & 0.962 & 0.942 & 0.952 & 0.960 & 0.958 & 0.966 & 0.948 & 0.946 & 0.963 \\
\hline Higuchi equation & $\begin{array}{l}\mathrm{K}_{\mathrm{h}} \\
\mathrm{R}_{\mathrm{h}}\end{array}$ & $\begin{array}{l}21.26 \\
0.984\end{array}$ & $\begin{array}{l}18.70 \\
0.991\end{array}$ & $\begin{array}{l}33.09 \\
0.968\end{array}$ & $\begin{array}{l}29.24 \\
0.981\end{array}$ & $\begin{array}{l}19.98 \\
0.984\end{array}$ & $\begin{array}{l}23.75 \\
0.989\end{array}$ & $\begin{array}{l}22.16 \\
0.961\end{array}$ & $\begin{array}{l}17.90 \\
0.979\end{array}$ & $\begin{array}{l}31.69 \\
0.986\end{array}$ \\
\hline
\end{tabular}

$\mathrm{K}_{\mathrm{z}}\left(\mathrm{mg} . \mathrm{h}^{-1}\right), \mathrm{K}_{\mathrm{f}}\left(\mathrm{h}^{-1}\right)$ and $\mathrm{K}_{\mathrm{h}}\left(\mathrm{mg} / \mathrm{cm}^{2} \cdot \mathrm{h}^{1 / 2}\right)$ are the release rate constants of zero-order, first order, and Higuchi model kinetics, respectively, as well as $\mathrm{R}_{\mathrm{z}}, \mathrm{R}_{\mathrm{f}}$ and $\mathrm{R}_{\mathrm{h}}$ are their corresponding correlation coefficients.

Table 4: Pharmacokinetic parameters of SFN commercial tablets and microspheres after oral administration at $10 \mathrm{mg} \mathrm{kg}^{-1} \mathrm{in} \mathrm{rats}$

\begin{tabular}{lll}
\hline Parameter & Commercial tablet & Microspheres \\
\hline$t_{1 / 2}(\mathrm{~h})$ & $11.87 \pm 5.21$ & $16.42 \pm 7.52$ \\
$\mathrm{AUC}_{0-\mathrm{t}}\left(\mu \mathrm{g} \mathrm{ml}^{-1} \mathrm{~h}^{-1}\right)$ & $5.61 \pm 0.45$ & $9.68 \pm 0.42$ \\
$\mathrm{AUC}_{0-\infty}\left(\mu \mathrm{g} \mathrm{ml}^{-1} \mathrm{~h}^{-1}\right)$ & $6.89 \pm 0.95$ & $13.47 \pm 1.23$ \\
$T_{\max }(\mathrm{h})$ & $3.15 \pm 0.87$ & $6.35 \pm 1.34$ \\
$C_{\max }\left(\mu \mathrm{g} \mathrm{ml}^{-1)}\right.$ & $0.62 \pm 0.12$ & $0.53 \pm 0.10$ \\
$\mathrm{MRT}_{0-\mathrm{t}}(\mathrm{h})$ & $8.51 \pm 1.65$ & $11.08 \pm 0.9$ \\
$\mathrm{MRT}_{0-\infty}(\mathrm{h})$ & $14.43 \pm 3.65$ & $19.78 \pm 5.54$ \\
${ }^{\mathrm{a}} \mathrm{P}>0.05$ & & \\
\hline
\end{tabular}

mean $\pm S D, n=6$

\section{Pharmacokinetic studies}

The study of pharmacokinetics in vivo could reveal the process and characteristics of drug absorption and metabolism in vivo. In this study, the self-made microspheres were used as a test product and compared with a reference product to study the pharmacokinetics in rats, and the relative bioavailability of the self-made preparations was enhanced. After the plasma samples were processed, the blood concentration-time 
data of the commercially available tablets and self-made microspheres were obtained. Table 4 shows the relevant pharmacokinetic parameters and fig. 6 depicts the average plasma concentration-time curves of the preparation. SFN from the reference tablet diffused into the systemic circulation $\left(T_{\max }=3.15 \mathrm{~h}\right)$, while SFN release from the floating microspheres was significantly prolonged $\left(T_{\max }=6.35 \mathrm{~h}\right)$.

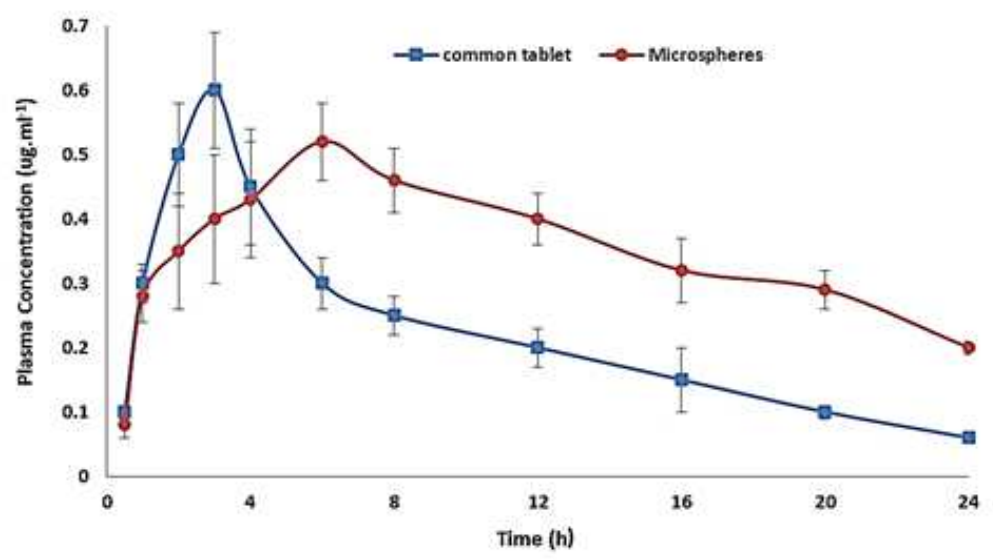

Fig. 6: Profiles of mean plasma drug concentration-time after oral administration of SFN commercial tablet and microspheres (mean \pm SD, $n=6)$

As compared with the reference tablet, the microspheres exhibited a decreased $C_{\max }$ and increased MRT. These data indicated that the $C_{\max }$ of the encapsulated SFN microspheres was lower than that of the common tablets. In addition, the peak time was delayed, and the retention time of the drug in vivo was also prolonged. The pharmacokinetic parameters are shown in table 4. T-tests for $\ln \mathrm{AUC}_{0-t}$ and $\ln C_{\max }$ showed that there were significant differences between the SFN microspheres $\left({ }^{*} \mathrm{P}>0.05\right)$ and ordinary tablets. Specifically, the peak concentration $\left(C_{\max }\right)$ was decreased, the peak time $\left(T_{\max }\right)$ was delayed, and the mean retention time (MRT) of the drug was prolonged. The relative bioavailability of SFN in the microspheres floating in the stomach was $196.0 \%$ at the same dose as the commercially available tablets.

\section{CONCLUSION}

Hollow microspheres could exhibit excellent floating and sustained release characteristics in vitro and improve SFN bioavailability in rats. The microspheres were prepared by an emulsion solvent evaporation technique using ether and ethanol as solvent, ethyl cellulose, and carbopol 934P as the encapsulating carrier. The optimized hollow microspheres with SFN showed high entrapment efficiency with small particle size diameter. The in vitro floating percentage of the microspheres was found to be $76.5 \%$ and floating after $12 \mathrm{~h}$, which ensured that the majority of the drug encapsulated in the hollow microspheres remained in the stomach. It could be observed from the SEM investigations that the core was hollow, which conferred buoyancy. The results of the pharmacokinetic study in rats with a high AUC 0 -t and prolonged $T_{\max }$ together demonstrated the enhanced bioavailability because of the prolonged gastric retention and sustained drug release.

\section{ACKNOWLEDGMENT}

I'm thankful to all industries for providing a sample of drug and excipients respectively. I'm thankful to my colleges for providing facilities to complete the research work.

\section{AUTHORS CONTRIBUTIONS}

Experimental designs, guidance, attention, support, help for the research work, Literature review, experimental work, optimization and interpretation of results was done by Dr. Mahmoud M. Ahmed.

\section{CONFLICT OF INTERESTS}

The author report no declaration of interest

\section{REFERENCES}

1. Baecker A, Liu X, La CV, Zhang ZF. Worldwide incidence of hepatocellular carcinoma cases attributable to major risk factors. Eur J Can Prev 2018;27:205-12.
2. Wu K, Wu H, Dai T, Liu X, Chen JF, Le Y. Controlling nucleation and fabricating nanoparticulate formulation of sorafenib using a high-gravity rotating packed bed. Ind Eng Chem Res 2018;57:1903-11.

3. Giglio V, Viale M, Bertone V, Maric I, Vaccarone R, Vecchio G. Cyclodextrin polymers as nanocarriers for sorafenib. Invest New Drugs 2018;36:370-9.

4. Sharma M, Kohli S, Dinda A. In vitro and in vivo evaluation of repaglinide loaded floating microspheres prepared from different viscosity grades of HPMC polymer. Saudi Pharm J 2015;23:675-82.

5. Ilyas R, Sapuan S, Sanyang ML, Ishak MR, Zainudin E. Nanocrystalline cellulose as reinforcement for polymeric matrix nanocomposites and its potential applications: a review. Curr Anal Chem 2018;14:203-25.

6. Gupta R, Pragapati S, Pattnaik S, Bhardwag P. Intend, depiction in vitro and in vivo appraisal of glipizide floating microspheses using ethyl cellulose and hydroxy propyl methyl cellulose as polymer by substantially modified method. Methods 2016;11:14.

7. Jain SK, Agrawal GP, Jain NK. Floating microspheres as drug delivery system: newer approaches. Curr Drug Delivery 2008;5:220-3.

8. Choudhury PK, Kar M, Chauhan CS. Cellulose acetate microspheres as floating depot systems to increase gastric retention of antidiabetic drug: formulation, characterization and in vitro-in vivo evaluation. Drug Dev Ind Pharm 2008;34:349-54.

9. Nilkumhang S, Alhnan MA, McConnell EL, Basit AW. Drug distribution in enteric microparticles. Int J Pharm 2009;379:1-8.

10. Soppimath KS, Kulkarni AR, Aminabhavi TM. Development of hollow microspheres as floating controlled-release systems for cardiovascular drugs: preparation and release characteristics. Drug Dev Ind Pharm 2001;27:507-15.

11. Wang K, Wang Y, Zhao X, Li Y, Yang T, Zhang X, et al. Sustained release of simvastatin from hollow carbonated hydroxyapatite microspheres prepared by aspartic acid and sodium dodecyl sulfate. Mat Sci Eng C 2017;75:565-71.

12. Zhang $\mathrm{C}, \mathrm{Xu} \mathrm{M}$, Tao X, Tang J, Liu Z, Zhang Y, et al. A floating multiparticulate system for ofloxacin based on a multilayer structure: in vitro and in vivo evaluation. Int J Pharm 2012;430:141-50.

13. Nehate C, Jain S, Saneja A, Khare V, Alam N, Dhar Dubey R, et al. Paclitaxel formulations: challenges and novel delivery options. Curr Drug Delivery 2014;11:666-86.

14. El-Menshawe S, Abdeltwab A, Mohamed A. Novel gastroretentive polymeric microspheres: an approach for increased bioavailability and an once daily dosing of terbutaline sulfate. Int J Pharm Pharm Sci 2016;8:320-9. 
15. Patel J, Patel D, Raval J. Formulation and evaluation of propranolol hydrochloride-loaded carbopol-934P/ethyl cellulose mucoadhesive microspheres. Iran J Pharm Res 2010;9:221.

16. Tawfeek HM, Abdel-Aleem JA, Ahmed MM. Development and optimization of itopride hydrochloride fast disintegrating tablets using factorial design and response surface methodology. Int J Pharm Sci Res 2015;6:1661.

17. El-Shenawy AA, Ahmed MM, Mansour HF, El Rasoul SA. Torsemide fast dissolving tablets: development, optimization using box-bhenken design and response surface methodology, in vitro characterization, and pharmacokinetic assessment. AAPS PharmSciTech 2017;18:2168-79.

18. Garud N, Garud A. Preparation and in vitro evaluation of metformin microspheres using non-aqueous solvent evaporation technique. Trop J Pharm Res 2012;11:577-83.

19. Ahmed MM, El-Rasoul SA, Auda SH, Ibrahim MA. Emulsification/internal gelation as a method for preparation of diclofenac sodium-sodium alginate microparticles. Saudi Pharm J 2013;21:61-9.
20. Jain S, Maheshwari R, Nema RK, Singhvi I. Development and validation of simple uv-spectrophotometric method of quantitation of indomethacin in solid dosage formulation using using mixed solvency concept. Pharma Innovation J 2017;6:453-6.

21. Das SK, Khanam J, Nanda A. Optimization of preparation method for ketoprofen-loaded microspheres consisting polymeric blends using simplex lattice mixture design. Mat Sci Eng C 2016;69:598-608.

22. Liu Y, Zhang J, Gao Y, Zhu J. Preparation and evaluation of glyceryl monooleate-coated hollow-bioadhesive microspheres for gastroretentive drug delivery. Int J Pharm 2011;413:103-9.

23. Rajinikanth PS, Karunagaran LN, Balasubramaniam J, Mishra B. Formulation and evaluation of clarithromycin microspheres for eradication of Helicobacter pylori. Chem Pharm Bull 2008;56:1658-64.

24. Vijayabhaskar K, Venkateswarlu K, Thirumalesh Naik S, Kiran Jyothi R, Nethra Vani G, Chandrasekhar K. Preparation and in vitro evaluation of ranitidine mucoadhesive microspheres for prolonged gastric retention. Br J Pharm Res 2016;10:1-12. 